4. Taylor, C. R., Heglund, N. C., McMahon, T. A. \& Looney, T. R. J. Exp. Biol. 86, 9-18 (1980)

5. Maloiy, G. M. O., Heglund, N. C., Prager, L. M., Cavagna, G. A. \& Taylor, C. R. Nature 319, 668-669 (1986)

6. Charteris, J., Scott, P. A. \& Nottrodt, J. W. Ergonomics 32, 1539-1550 (1989).

7. Heglund, N. C., Willems, P. A., Penta, M. \& Cavagna, G. A. Nature 375, 52-54 (1995).

8. Bennett, M. B. \& Taylor, G. C. Nature 378, 56-59 (1995).

9. Kram, R. \& Taylor, C. R. Nature 346, 265-267 (1990).

\section{Stabilizing gaze in flying blowflies}

When the gaze is moved quickly, vision becomes blurred and the way in which three-dimensional structures are seen can be affected ${ }^{1}$. How can these effects be minimized? During flight, blowflies (Calliphora vicina) turn both the head and the thorax very quickly, producing gaze shifts which affect vision. Here we show that blowflies reduce the effects of thorax movements on vision by moving the head later, and more quickly, than the thorax. This reduces the time in which gaze is shifting relative to the surroundings, and maximizes the time available for analysing the surroundings.

Gaze shifts present a challenge to vision for at least two reasons. First, it takes time for optic signals to be integrated by the photoreceptors in the eye. If the gaze is shifted, this integration time will result in a blurred image being produced, particularly during fast gaze shifts. Second, the resulting rotational flow of optic signals will interfere with the pattern of optic flow that normally reveals the three-dimensional structure of the surroundings during linear motion ${ }^{1}$.

Blowflies can move their two compound eyes by moving the head ${ }^{2,3}$. The head, which is connected to the thorax by a neck, has appreciable freedom of movement under muscular control ${ }^{4,5}$. We measured the position and orientation of thorax and head during (almost) free flight by using a modified search coil technique ${ }^{6}$. The thorax usually changes course through a series of short, fast turns ${ }^{7}$, with gradual course

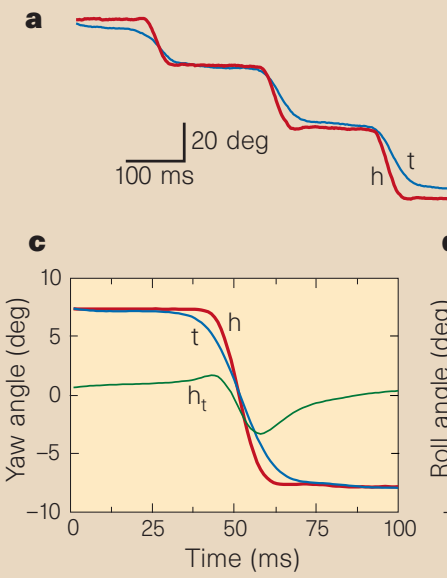

b
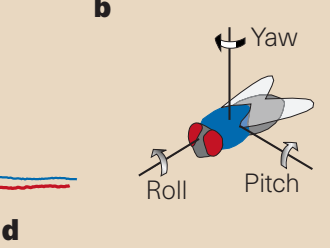

d

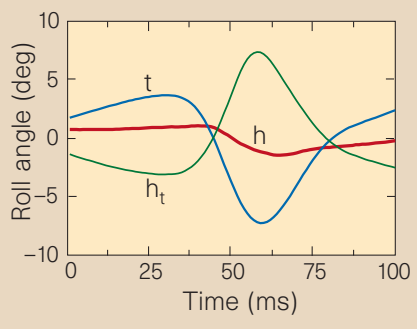

100

flies); $h_{t}$ shows yaw or roll of head relative to thorax.

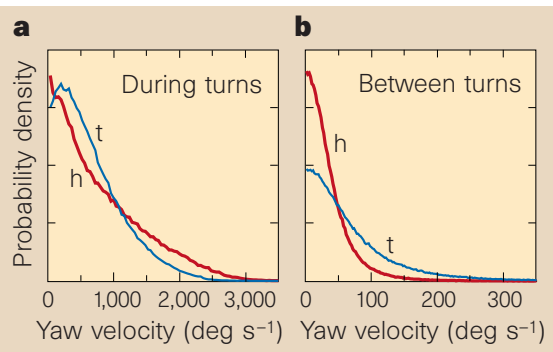

Figure 2 Gaze stabilization between turns. a, Probability densities of yaw velocities during turns, showing that yaw velocities of the head (h) reach higher values than those of the thorax (t). Total flight time was 703 seconds by four flies, during which time 6,697 turns were made. b, Between turns, yaw velocities of the head are significantly lower than those of the thorax, and both are much lower than during turns. More detailed figure legends are available as Supplementary information.

and the angular resolution of the photoreceptors is 1-2 degrees, angular velocities higher than 100-200 degrees per second will cause significant blur in the fly's visual system. The high angular velocity of the head during turns therefore makes it impossible to see details. Between turns, however, the head is more stable than the thorax (Fig. 2b), mostly within a velocity range that gives little blur attributable to rotation.

The triphasic movement of the head in the yaw direction (Fig. 1c) probably acts to maximize the periods of stable gaze by minimizing the duration of the gaze shift. The extra angular velocity produced by the neck muscles is effective because it peaks at about the same time as the peak of the thorax angular velocity. The effective duration of the most common gaze shifts is not much longer than the integration time of the photoreceptor. Because at least one integration period is lost by making a gaze shift anyway, the roughly 1.5 integration periods lost during a typical blowfly turn seem to be a reasonable compromise between minimal visual impediment and very fast movement.

\section{Schilstra, J. H. van Hateren}

Department of Neurobiophysics,

University of Groningen,

Nijenborgh 4, 9747 AG Groningen, The Netherlands e-mail: hateren@bcn.rug.nl

1. Koenderink, J. J. Vision Res. 26, 161-180 (1986).

2. Land, M. F. Nature 234, 299-300 (1973).

3. Geiger, G. \& Poggio, T. Biol. Cybernet. 25, 177-180 (1977).

4. Hengstenberg, R. in The Head-Neck Sensory Motor System (eds Berthoz, A., Graf, W. \& Vidal, P. P.) 49-55 (Oxford Univ. Press, 1992).

5. Strausfeld, N. J., Seyan, H. S. \& Milde, J. J. J. Comp. Physiol. A 160, 205-224 (1987).

6. Schilstra, C. \& van Hateren, J. H. J. Neurosci. Methods (in the press).

7. Wagner, H. Phil. Trans. R. Soc. Lond. B 312, 527-551 (1986).

8. Carpenter, R. H. S. Movements of the Eyes (Pion, London, 1988).

9. Hengstenberg, R. J. Comp. Physiol. A 163, 151-165 (1988).

10. Haslwanter, T. Vision Res. 35, 1727-1739 (1995).

Supplementary information is available on Nature's World-Wide Web site (www.nature.com) or as paper copy from the London editorial office of Nature. 